\title{
UPAYA PENEGAKAN HUKUM DAN KEADILAN \\ (Perspektif Sosio-Historis Islam)
}

\author{
M. Sulthon \\ IAIN Sunan Ampel Surabaya \\ Sulthonmuhammad99@yahoo.co.id
}

\begin{abstract}
Abstrak
Tujuan utama Eera Regormasi di Indonesia adalah penegakan hukum dan keadilan. Namun pada kenyataannya hal itu belum berjalan maksimal. Indikasinya masih banyak kasus jual beli putusan pengadilan, kekecewaan pada pihak yang berperkara, serta anarkisme yang di sebabkan putusan pengadilan yang kurang tepat.

Dalam perspektif sosio-historis Islam, tulisan ini memberikan tawaran pemikiran bahwa upaya penegakan hukum dan keadilan diperlukan langkah-langkah sebagai beriktu: pertama, merekonstruksi hukum yang selama ini cenderung bercorak positivistik dengan pendekatan yuridis formal, dengan pengayaan pada etic-substanttive-pragmatic: kedua, sumber daya manusia dari penegak hukum yang memiliki komitmen moral untuk menempatkan supremasi hukum dan keadilan bagi masyarakat; dan ketiga, adanya political-will dan good-will darai para pemimpin politik dan pemerintahan.
\end{abstract}

Kata Kunci: Upaya Penegakan Hukum dan Keadilan. 


\section{A. Pendahuluan}

Ikhtiar untuk melakukan penegakan hukum di negara kita merupakan fokus utama dalam proses reformasi, tetapi kenyataannya upaya itu masih belum menunjukkan hasil yang maksimal, untuk tidak menyatakan masih sebatas retorika pejabat, para pemerhati hukum, penegak hukum dan tidak kurang Presiden pernah mengatakan bahwa di Indonesia ini tumbuh subur "mafia atai mafia peradilan". Hukum dapat dipermainkan, vonis atau keputusan hukum dapat diperjualbelikan.

Tidak jarang terjadi, persoalan yang murni hukum, tiba-tiba kandas begitu saja, akibat intervensi kepentingan-kepentingan politik tertentu, memang disadari sepenuhnya bahwa tidak mudah membuktikan adanya "mafia perdailan" atau "jual beli vonis hakim". Bahwa suatu perbuatan yang jelas-jelas merupakan pelanggaran terhadap norma-norma hukum, susila, dan etika, aparat penegak hukum "Terpaksa harus" menanggung rasa untuk dapat melakukan tindakan hukum, karena penyelesaia secara drastis dan frontal, akan berakibat muncul permasalahan baru yang tidak kalah rumitnya.

Masih banyak lagi kasus-kasus besar yang menimpa 'orang-orang besar" tidak banyak yang sampai pada ujung penyelesaiannya, sementara ketika sebuah perkara menimpa masyarakat kecil, persidangan dan vonis pengadilan pun berjalan dengan lancer. Ada 14 kendala penegakan hukum di Indonesia, ${ }^{1}$ yaitu:

1. Ketatanegaraan yang menempatkan jaksa agung sejajar dengan menteri;

2. Sistem perundangan yang belum memadai;

3. Factor sumber daya manusia;

4. Factor kepentingan yang melekat para aparat pelaksana, baik itu kepentingan pribadi, golongan, maupun politik kenegaraan;

5. Corpsoiest dalam institusi

6. Tekanan yang kuat kepada aparat penegak hukum;

7. Faktor budaya;

8. Factor agama;

9. Legislative sebagai "Lembaga legislasi" kurang memberi contoh tauladan yang baik dalam penegakan hukum;

\footnotetext{
1 Masatria Liba, 14 Kendala Penegakkan Hukum, Mahasiswa dan Pemuda Pilar Reformasi Tegaknya Hukum dan HAM (Jakarta: Yayasan Annisa, 2002), hal 26-48.
} 
10. Kemasan politik pemerintah

11. Factor kepemimpinan;

12. Kuatnya jaringan kerjasama pelaku kejahatan;

13. Kuatnya pengaruh kondisi dalam jiwa pensiunan aparat penegak hukum, dan

14. Pemanfaatan kelemahan peraturan perundang-undangan.

Tidak berjalannya secara maksimal upaya hukum di negeri ini, membawa implikasi yang cukup serius, yakni munculnya apatisme hukum dalam masyarakat yang berakibat timbulnya anarkhi, fenomena amuk massa atau tindakan main hakim sendiri oleh sebagian masyarajat, adalah gambaran nyata dari pesimisme dan apatisme masyarakat terhadap stagnasi penegakan hukum dan keadilan.

Ada sebagian pendapat menyatakan bahwa ketidakberdayaan penegakan hukum dan keadilan di Negara kita ini, salah satunya adalah kerana corak dan format hukum yang positivistik. Kebenaran dilihat dan diukur lebih pada kebenaran formal dan prosedural, tanpa menimbang tepa selira kepada rasa keadilan dalam masyarakat.

.Faktor lain yang turut menyebabkan maandegnya penegakan hukum dan keadilan adalah sumber daya manusia dlam penegakan hukum, aparat penegak hukum kurang atau tidak cukup memiliki integritas moral dan komitmen yang tinggi dalam mewujudkan rasa keadilan dalam masyarakat, sudah terlalu banyak terjadi, rasa keadilan masyarakat dilukai, karena pertimbaangan-pertimbangan pragmatis politik, penegakan supremasi hukum harus dikorbankan.

Berbagai pelanggaran dalam proses penegagkan hukum tekah terjadi seperti suap, jual beli keputusan hakim dan ketidakadilan hukum. Jika demikian halnya, dari mana harus dimulai suatu ikhtiar untuk untuk menegakkan hukum dan keadilan adalah pekerjaan besar namun mulia dan menuntut kesungguhan kita secara bersama-sama secra simultan. Prof. Sucipto Roharjo, Begawan Sosiologi Hukum Universitas Diponegoro Semarang menegaskan, hukum bukan hanya untuk kepentingan hukum itu sendiri, akan tetapi hukum haruslah membahagiakan masyarakat. ${ }^{2}$

\footnotetext{
${ }^{2}$ Sucipto Raharjo, Hukum dan Masyarakat, (Bandung: Angkasa, 1980), hal. 130-135
} 


\section{B. Rambu-rambu Hukum Islam}

Islam menggariskan bahasa penegakan hukum bias berjaalan dengan baik, menuntut sumber daya manusia yang committed terhadap pelaksanaan amanat dan keadilan. Sesungguhnya Allah menyuruh kamu menyampaikan amanat kepada yang berhak menerimanya, dan (menyuruh kamu) apabila menetapkan hukum di antara manusia supaya kamu menetapkannya dengan adil. ${ }^{3}$

Karena itu untuk dapat melakukan ikhtiar penegakan hukum dan keadilan tersebut, dibutuhkan adanya political will dan good-will para pemimpin bangsa ini secara bersungguh-sungguh dan konsisten. Dalam konteks ini pula al-Quran menempatkan perintah kepada masyarakat untuk taat kepada ulil amri, pada ayat 59 surat an-nisa', apabila ulil amri didalam melaksanakan tugas-tugas dan programnya, termasuk penegakan dan keadilan sejalan dengan perintah Allah dan Rasul-Nya.

Menurut Ibn Taimiyah, ${ }^{4}$ dua kata kunci yang harus dipegang, yakni menjalankan amannat kepada yang berhak dan menegakkan hukum secara adil sebagaimana dimaksud QS An-nisa' (4):58 mewajibkan kepada kita untuk memenuhi amanat kepada yang berhak dan menegakkan hukum secara adil. Duaa hal tersebut merupakan satu kesatuan politik yang adil dan kekuasaan yang baik yang tidak bisa dipisah-pisahkan.

Kata adil atau "adl disebutkan dalam al-Quran tidak kurang dari dua puluh delapan kali. Secara harfiyah adil artinya lurus, tegak atau tidak condong. Adil bisa dipahami sebagai memberikan hak kepada yang berhak menerimanya atau menempatkan sesuatu pada tempatnya.

Berbuat adil adalah kewajiban baik kepada diri sendiri, kepada orang lain, maupun kepada Allah, inilah yang oleh ibn'Araby dielaborasi pertama, adil dalam hubungan hamba dengan tuhannya, adanya hamba senantiasa mengutamakan hak tuhannya dibanding haknya sendiri, kedua, adil dengan hubungan diri sendiri, yang berarti melarang diri sendiri dari

\footnotetext{
${ }^{3}$ QS. Al-Annsia'; 4:58

${ }^{4}$ Ibn Taimiyah, Al-Siyasah, al-Syari'yyah, fi Ishlah, al-Ra'iywa, al-Ra'iyyah, (Beirut: Dar Al-Fikr alHadits, tt), hal. 12
} 
semua yang mengandung bahaya, ketiga, adil dalam berhubungan dengan makhluk lain, seperti menghindari khianat dan perbuatan yang mengganggu.

Dalam komunitas Negara bangsa, maka pihak yang paling bertanggung jawab atas penegakan hukum dan keadilan adalah pejabat Negara dan pemerintah. Secara harfiyah, pemerintahan yang dalam bahasa arab digunakan kata hikmah, satu akar kata dengan al-hakim artinya hakim atau aparat yang menegakkan hukum. Dari sini pemerintah memiliki tugas pokok untuk menegakkan hukum dan keadilan, dalam redaksi lain Rasyid Ridha mengidentikkan al-amanah dengan al-imarah, atau al-imanah al-adhma yang memiliki tugas utama menjaga agama dan mengatur urusan dunia. ${ }^{5}$

Upaya penegakan hukum pada masa Rasulullah dan Khulafa al-Rasyidin banyak kasus yang di hadapi pada zaman Rasulullah SAW kadang beliu sendiri yang menyelesaikan dan kadang melimpahkan otoritas peradilan untuk memutuskan perkara kepada para sahabat. Perkara-perkara yang diajukan meliputi perkara warisan, utang piutang, sengkata tanah, pidana perizinan, nafkah istri, pidana pembunuhan, dan sengketa air. Tidak ada keraguan sedikitpun pada masa Rasulullah SAW., penegakan hukum berjalan dengan baik, para sahabat yang ditugasi menjadi hakim, juga dengan sungguh-sungguh menjalankannya dengan penuh tanggung jawab.

Rasulullah SAW. sangat tegas dalam menegakkan hukum dan keadilan. Beliau tampaknya menenggarai adanya kecenderungan untuk menegakkan hukum hanya untuk kalangan masyarakat bawah, sementara untuk kaum bangsawan atau pejabat tidak dilaksanakan, ini dapat dilihat dalam riwayat al-Bukhori dari Aisyah: "Usamah melaporkan kepada nabi SAW. tentang seorang perempuan, beliu menegaskan: "sesungguhnya akan hancur orang-orang (umat) sebelum kalian, karena mereka memperlakukan hukuman (hudud) bagi orang-orang lemah (al-wadl'i) dan mereka meninggalkan (penerapan hukuman) orang-orang yang berkedudukan tinggi (al-syarif), dan demi Zat yang diriku di genggaman-Nya, sekiranya Fatimah (anakku) melakukan demikian (mencuri) sungguh aku akan memotong tanggannya."6

\footnotetext{
${ }^{5}$ Rasyid Ridha; al-Khilafah al-Imanah al-Udhma (Mesir, Mathba'ah al-manar, tt), hal. 10

${ }^{6}$ Al-Bukhari; Shahih al-Bukhari: Juz II (Beirut; dar al-fikr, 1981), hal. 16
} 
Sepeninggal Rasulullah SWA setelah melalui perdebatan yang panjang dan alot di tsaqifah bani saidah, akhirnya Abu Bakar as-Siddiq dipilih menjadi pengganti beliu. Disinilah awal kata "khalifa" digunakan sebagai peran teknis, sebagai jabatan politik untuk menggantikan Rasulullah SAW. dan tugas-tugas profetik, berupa melindungi agama (harasah al-din) dan mengatur urusan dunia (siyasah al-dunya).

Abu bakar as-Siddiq (573-634 M) yang berkuasa tidak lama, pada masa awal jabatannya dihadapkan pada munculnya "gerakan" orang-orang murtad dan orang-orang pembohong untuk membayar zakat, mengirim tentara untuk menaklukkan Syam dan Iraq. ${ }^{7}$ Tetapi kesungguhan abu bakar untuk menegakkan hukum dan keadilan begitu nyata. Bahkan tidak segan-segan menyerahkan harta pribadinya untuk baitul mal demi kepentingan Islam dan umatnya.

Pada masa Umar Ibn Al-Khattab, dimulai usaha untuk memisahkan antara kekuasaan Eksekutif dan Yudikatif. Diantara hakim yang diangkat adalah Abu Darda di Madinah, Syuraih Ibn Qais di Mesir, hakim-hakim ini diserahi menangani perkara-perkara perdata, sementara untuk perkara pidana masih ditangani oleh Kalifah dan penguasa daerah.

Umar juga menyusun dustur peradilan atau disebut dengan dustur Umar atau risalah al-Qadla' yang dikirim kepada Abu Musa Al-asya'ry berisi tentang pokok-pokok penyelesaian perkara di muka sidang. ${ }^{8}$

Disamping menyusun dustur pengadilan, Umar juga yang meletakkan dasar-dasar penetaan pemerintahan. Pada tahun 641 membentuk dewan kantor catatan daftar gaji guna memudahkan pembagian gaji, itu sebabnya ia disebut sebagai peletak dasar-dasar perpajakan yang sering disebut Al-Kharaj. ${ }^{9}$

Dustur Umar inilah yang kelak menjadi referensi para hakim pada masa-masa sesudahnya prinsip-prinsip penting yang dikemukakan dalam dustur tersebut antara lain adalah:

\footnotetext{
${ }^{7}$ Hasbi Asl-Shiddiq, Peradilan dan Hukum Acara Islam (Bandung: Al- Maarib, 1964), hal. 15

${ }^{8}$ M. Salam Madzkun, Tarikh al-Qadla' fi al-Islam, Terj. Imron AM, (Surabaya: Bina IImu, tt), hal. 42-43

${ }^{9}$ Noul J. Coulson: Hukum Islam dalam Perspektif Sejarah, Terj. Hamid Ahmad, (Jakarta: P3M, 1987),
} hal. 137 
1. Orang yang memutuskan hukum harus paham dulu perkaranya, karena tidak ada artinya bicara soal keadilan tanpa ada pelaksanaannya.

2. Sama ratakan pihak-pihak yang berperkara dalam majelismu, dalam pandanganmu, dalam keputusanmu, sehingga orang yang berpangkat tidak akan mengharapkan penyelewenganmu, dan orang yang lemah tidak sampai putus asa mendambakan keadilanmu.

3. Bukti itu wajib atas penggugat atau penuduh, sedang sumpah wajib atas pihak yang menolak tuduhan atau gugatan.

Usman Bin Affan dikenal sebagai khalifah yang membangun gedung pengadilan, yang pada pendahulunya menjalankan pengadilan di masjid. Usman dikenal sangat dermawan, mempersiapkan tentara dengan hartanya sendiri, selain dikenal sebagai tokoh yang membukukan al-Qur'an, juga dikenal sebagai orang pertama yang menambah bangunan masjid al-Haram dan Masjid Nabawi.

Ali Bin Abi Thalib adalah Khalifah ke empat, yang sejak Rasulullah SAW, masih hidup pernah ditugasi sebagai hakim, kemunculannya sebagai khalifah akibat terbunuhnya Usman bi Affan membawa iklim politik dan pemerintahannya berjalan tidak stabil. Nuansa politik begitu kental menyelimuti hari-hari pelaksanaan tugasnya. Muawiyah menuntut pertanggungjawaban atas terbunuhnya Usman, dan memang tidak mudah untuk membuktikan siap sesunggunya pelaku pembunuhan Usman itu. Peristiwa pembunuhan Usman inilah oleh sejarah dicatat sebagai fitnah al-kubra dalam lembaran sejarah islam.

Ilsutrasi di atas, memberikan gambaran yang jelas, bahwa penegakan hukum dan keadilan mendapat tempat yang sangat terhormat. Dalam pelaksanaannya juga selain mengedepankan hukum, keadilan dan kesejahteraan masyarakat tidak bias diabaikan begitu saja.

\section{Membangun Mazhab Alternatif}

Perdebatan paradigmatic tentang definisi dan tujuan hukum diantara mazhab hukum kelihatannya masih mewarnai wacana intelektual kita. Mazhab ilmu hukum murni yang dipelopori oleh kelsen (1881) menentang filsafat dan berkeinginan menciptakan ilmu hukum 
murni, menegakkan semua materi yang tidak relevan, dan memisahkan yurispredensi dari ilmu sosial. Karena menurutnya ilmu hukum adalah studi tentang sifat norma-norma yang ditegakkan oleh hukum. Jadi etika dan filsafat sosial jauh dari hukum.

Mazhab positivisme yang di awali oleh pemikiran auguste comte (1798-1875) lebih menekankan pada penolakan semua konstruksi hipotesis didalam filsafat dan membatasi diri pada observasi empiric dan hubungan fakta-fakta di bawah panduan metode-metode yang dipergunakan dalam ilmu-ilmu alam. ${ }^{10}$

Mazhab realis Amerika yang juga disebut positivisme pragmatis menegaskan hukum harus ditentukan oleh fakta-fakta sosial yang mengalami peerubahan terus-menerus, yang menempatkan bukan yang seharusnya.

Mencermati pemikiran mazhab-mazhab hukum tersebut di atas, pemikiran hukum Indonesia tampaknya lebih banyak "terjebak" pada positivisme analitik ketimbang pragmatis-empirik. Meskipun ada upaya menempatkan perkambangan nilai-nilai yang tumbuh dalam kesadaran masyarakat menjadi bagian lain hukum yang berlaku. Sistem hukum yang positivistik memunculkan budaya hukum yang formalistik. Ide-ide keadilan yang menjadi tujuan hukum tidak cukup terakomodasi dengan baik. Maka yang terjadi adalah banyak putusan pengadilan memilikii kepastian hukum tetapi menusuk rasa keadilan masyarakat.

Dalam perspektif sosio-historis Islam, hukum diformulasikan sarat dengan muatan nilai kemaslahatan dan keadilan. Konsep al-Dlaruriyat al-Khamsah seperti dikemukakan oleh imam al-Juwaini dan al-Ghazali menjelaskan bahwa hukum dilegalisasikan adalah untuk kepentingan memelihara agama (hifdh al-din), memelihara jiwa (hifdh al-nafs), memelihara aakl (hifdh al-'aql), memelihara harta (hifdh al-mal) dan memelihara keturunan (hifdh al-nasl). ${ }^{11}$

Karena itu, dalam memformulasikan hukum yang berwatak Indonesia, jika diperdebatkan eklektik menjadi satu pilihan, maka pengayaan terhadap materi-materi hukum dengan konsep kemaslahatan dalam hukum islam dapat dilakukan ${ }^{12}$. Atau meminjam bahasa Prof. Satjipto Rahardjo, hukum haruslah membahagiakan masyarakat, yang dalam

\footnotetext{
10 Yasmil Anwar \& Adaug, Pembaruan Hukum Pidana, (Jakarta: Gramedia, 208) hal. 1-5

${ }^{11}$ H. Faturrahman Djamil, Filsafat Hukum Islam, (Jakarta: Logos Wahana Ilmu, 1999), hal. 123-131

${ }^{12}$ A. Qadri Azizy, EkletismeHukum Nasional. (Yogayakarta: Gama Media, 2002), hal. 247-252
} 
terminologi, ushul fiqh hukum haruslah bermuara kepada merealisasikan kemaslahatan masyarakat.

Dalam penerapan hukum, aparat perlu mempertimbangkan psiko-sosial masyarakat sebagai pelaku hukum. Dalam hukum Islam dikenal konsep “Azimah”, artinya hukum yang berlaku dalam situasi normal, yang berbeda halnya dengan apabila situasi normal, Umar ibn al-Khattab mislanya, pernah tidak menjatuhkan hukuman potong tangan kepada Ubaid pembantu Hathib ibn Abi Albata'ah mencuri unta untuk dimakan, dalam riwayat lain, pembantu Hathib mencuri unta seorang laki-laki dari Madinah, mereka bersama-sama menyembelih. Kasus ini kemudian dilaporkan keepada Umar. Umar memerintahkan kepada Katsir Ibn al-Shalat agar memotong tangan mereka. Akan tetapi setelah diinformasikan bahwa mereka melakukan pencurian itu karena kelaparan, maka umar tidak jadi melaksanakannya. ${ }^{13}$

Untuk dapat mewujudkan upaya tersebut ada beberapa factor yang perlu di perhatikan. ${ }^{14}$ Pertama ,persepsi penegak hukum terhadap masyarkat,agar tidak lagi sebagai sasaran tetapi mereka adalah pemegang peran .kedua,penegak hukum hendaknya melakukan perubahan terhadap makna, kedudukan dan fungsi kekuasaan, aparat hendaknya menjadi pelayan masyarakat untuk mencerdaskan mereka,sehingga akan tumbuh budayah hukum yang sehat .ketiga aparat penegak hukum perlu menyadari bahwa masyarakat makin kritis dan tidak lagi bisa dianggap remeh

Dalam khazanah hukum islam, dikenal term ijtihat atau kerja intelektual untuk memformulasikan hukum dalam menjawab persoalan yang timbul dalam masyarakat. Ini di maksudkan, aparat penegak hukum tidak di benarkan, dengan dasar tidak atau belum ada ketentuan hukum yang mengatur, kemudian membiarkan persoalan hukum tanpa jawaban atau solusi

\section{Kesimpulan}

Bahwa dalam upayah menegakkan hukum dan keadilan, dibutuhkan kerja keras konsisten dan komitmen yang tinggi dari aparat penegak hukumnya. diawali dari upaya

\footnotetext{
${ }^{13}$ Muhammad Rawas Qal'ah, mausu'ah Fiqh Umar Ibn Al-Khattab, (Beirut> Dar Al-Nafais, 1989), h1l. 491

14 Esmi Warasih, Pemberdayaan Masyarakat dalam Proses Penegakan Hukum dan Persoalan Keadilan, (makalah disampaikan dalam orientasi Kader Ulama Majelis Ulama Indonesia Propinsi Jawa Tengah, Semarang: 26 Juli 2004)
} 
merekonstruksi hukum yang selama ini cenderung bercorak positivistik dengan pendekatan yuridis formal, dengan pengayaan pada etic-subtantive-pragmatic dengan mengambil bahan baku dari sistem hukum manapun, yang sesuai dengan masyarakat Indonesia yang mejemuk termasuk hukum islam yang kerakteristiknya tidak terpisahkan dari nilai nilai taransedetal sebagai penjabaran dari konsep "rahmatan lilalamin"

Agar upayah penegakan hukum dan keadilan dapat berjalan dibutuhkan adaya political-will dan good will dan integritas moral yang memadai dari para pemimpin politik dan pemerintahan, mengingat peran, tugas, dan fungsi para pemimpin ini sangat besar dan efektik. Memang harus segera di sadari, upayah demikian membutuhkan sumber daya manusia yang memiliki komitmen moral untuk menempatkan supremasi hukum dan keadilan bagi masyarakat 


\section{Daftar Pustaka}

\section{Al-Qurannul Karim}

Al-Bukharu, 1981, Shahih Al-Bukhari, Beirut: Dar al-Fikr.

Qadri Azizy, 2002, Ekletisisme Hukum Nasional. Yogyakarta: Gama Media

Faturrahman Djamil, 1999, Filsafat Hukum Islam, Jakarta: Logos Wahana Ilmu

Esmi Warasih, 26 Juli 2014, Materi Makalah Pemberdayaan Masyarakat dalam Proses Penegakan Hukum dan Persoalan Keadilan, disampaikan dalam Orientasi Kadel Ulama Majelis Ulama Indonesia Propinsi Jawa Tengah, Semarang.

Hasbi Asl-Shiddiq, 1964, Peradilan dan Hukum Acara Islam, Bandung: Al-Maarib

Ibn Tamiyah, tt, Al-Siyasah, Al-Syar'iyyah, Fi Ishlah, Al-Ra'iyyah, Beirut: Dar al-fikr al-Haditz.

M. Salam Madzkur, tt, Tarikh al-Qadla’ fial-Islam (terj. Imron AM), Surabaya: Bina Ilmu.

Masatria Liba, 2002, 14 Kendala Penegak Hukum; Mahasiswa dan Pemuda Sebagai Pilar Reformasi Tegaknya Hukum dan HAM, Jakarta: Yayasan Annisa'.

Muhammad Rawas Qal'ah, 1989, Mausu'ah Fiqh Umar Ibu al-Khattab, Beirut: Dar Al-Nafais

Noul J. Coulson, 1987, Hukum Islam dalam Perspektif Sejarah, (Terj. Hamid Ahmad), Jakarta: P3M

Rasyid Ridha, tt, Al-Khilafah Al-Imamah Al Udhma, Mesir: Mathba'ah Al-Manar.

Sucipto Rahardjo, 1980, Hukum dan Masyarakat, Bandung: Angkasa

Yasmil Anwar \& Adaug, 20008, Pembaruan Hukum Pidana, Jakarta: Gramedia 